\title{
Histopathological study of breast lesions
}

\author{
Sulhyan K.R. ${ }^{1}$, Anvikar A.R. ${ }^{2}$, Mujawar I.M. ${ }^{3}$, Tiwari H. ${ }^{4}$ \\ ${ }^{1}$ Dr. (Mrs.) Kalpana Ranjitsingh Sulhyan, Professor and Head, ${ }^{2}$ Dr. Arti Rameshrao Anvikar, Assistant Professor, \\ ${ }^{3}$ Dr. Imran Mahamadisak Mujawar, ${ }^{4}$ Dr. Hitesh Tiwari, Junior Resident, All authors are affiliated with Department of \\ Pathology, Government Medical College, Miraj, Maharashtra, India.
}

Address for Correspondence: Dr Hitesh Tiwari, Email: hitesh_dr2007@yahoo.co.in

\begin{abstract}
Objectives: To study the histopathological features of neoplastic and non neoplastic lesions of breast. To correlate the pathological findings with clinical parameters. Design and methods: We have studied total 161 cases of breast lesions over a period of two years in our institute. The specimens were received in histopathology section of our department. Detailed gross examination of specimens was done followed by fixation, thorough sampling, and tissue processing. The different lesions were studied by histopathological examination and analysed. Neoplastic lesions were classified according to the WHO classification (2012). Results: Out of the 161 cases, 128 cases had neoplastic lesions and 32 cases had non-neoplastic lesions, and one case had coexistent neoplastic and nonneoplastic lesions. Two cases had dual neoplastic lesions. Out of the total 129 cases with neoplastic lesions, 76 cases had benign breast tumors, 53 cases had malignant breast tumors, and 2 cases had precursor lesions. Fibroadenoma was the most common benign tumour with 60 cases. Invasive carcinoma no special type was the most common malignant tumour with 43 cases. Special subtypes of invasive carcinoma found in our study were metaplastic carcinoma ( 3 cases) and mucinous carcinoma ( 1 case). The most common nonneoplastic lesion was mastitis with 12 cases, followed by duct ectasia and fibrocystic change. There were 4 cases of gynaecomastia. All the tumors involved upper outer quadrant most frequently. The benign tumors were most frequent in second, third and fourth decades, malignant tumours were seen beyond $4^{\text {th }}$ decade. The nonneoplastic lesions were common in $4^{\text {th }}$ decade. Conclusion: Histopathological study is important in the management of breast lumps
\end{abstract}

Keywords: Breast, Invasive carcinoma, Fibroadenoma, Ductal carcinoma in situ, mastitis Histopathological Study of Breast Lesions.

\section{Introduction}

Breast is a site of a broad array of pathological alterations. Advances in imaging techniques and increased use of fine needle aspiration cytology have greatly assisted the preoperative evaluation of breast lesions. However, in a large proportion of cases differentiation between benign and malignant lesions still rests on histopathological examination. Cancer of breast is one of the most common neoplasms in females [1]. In India, breast cancer is second most common cancer after cervical cancer [2]. Recognition of different neoplastic and nonneoplastic breast lesions is important for the differential diagnosis from malignant lesions and ultimately for the management of the patients with breast disease.

Manuscript received: $27^{\text {th }}$ December 2016

Reviewed: $3^{\text {rd }}$ January 2017

Author Corrected: $9^{\text {th }}$ January 2017

Accepted for Publication: $16^{\text {th }}$ January 2017
We have studied and analysed various neoplastic and nonneoplastic breast lesions from the specimens received in our histopathology section and correlated the histopathology with clinical parameters.

\section{Material and Methods}

The present study was a prospective study of 161 cases undertaken at the department of pathology in our institute. The specimens were received in different forms such as excisional biopsy [97 cases], modified radical mastectomy [44 cases], simple mastectomy [6 cases], ulcer edge biopsy [9 cases], trucut biopsy [2 cases], quadrantectomy [2 cases] and microdochectomy specimen [1 case]. The clinical information was obtained from the biopsy requisition forms and the indoor case papers. Detailed gross examination was 
done and the specimens were fixed in $10 \%$ formalin followed by thorough sampling. For malignant tumors, the deeper surface was inked for examination of deep surgical margin. After fixation, representative tissue bits were taken from tumor proper, nipple and areola, deep surgical margin, adjacent breast and lymph nodes if available. The tissue bits were processed to make paraffin blocks. The sections were cut at 3-4 micron thickness and were stained with Hematoxylin and Eosin. Microscopic examination was done.
The neoplastic lesions were classified according to WHO classification 2012[1]. Invasive breast carcinoma was graded according to Nottingham modification of Bloom -Richardson grading system. The neoplastic lesions were analysed according to age distribution, quadrant involvement, nature of specimen, and histopathology. The non neoplastic lesions were studied according to the age distribution and histopathology. Mastitis was further analyzed according to its types.

\section{Results}

Histopathological analysis of all the cases is shown in Table no. 1. Of the total 161 cases, 128 cases had neoplastic lesions, 32 cases had nonneoplastic lesions and 1 case had coexistent neoplastic and non-neoplastic lesions. Two cases had dual neoplastic lesions. Total 76 benign tumors were found. Fibroadenoma (figure 1) was the most common benign tumor followed by hamartoma (figure 2). Total 53 malignant tumors were observed. The vast majority of cases with malignant breast tumors had invasive carcinoma, no special type (43 cases) (figure 3). The special subtypes encountered were metaplastic carcinoma (3 cases) (figure 4) and mucinous carcinoma (1 case) (figure 4). One case of metaplastic carcinoma also had Paget disease of nipple. One case of invasive carcinoma, no special type had coexistent tuberculous mastitis (figure - 5). Two patients had Ductal carcinoma in situ with microinvasion (80 year female and 58 year female). One of these had high grade DCIS with microinvasion which was proved with the help of immunohistochemistry. Two cases of ulcer edge biopsy were diagnosed as unclassified carcinoma. There was one case of undifferentiated pleomorphic sarcoma.

Table No.-1: Showing histopathological analysis of all cases.

\begin{tabular}{|c|c|c|c|}
\hline Category & Diagnosis & No. of cases & Percentage $(\%)$ \\
\hline \multirow[t]{7}{*}{ Benign tumors } & Fibroadenoma & 60 & 37.26 \\
\hline & Hamartoma & 8 & 4.96 \\
\hline & Multiple duct papilloma & 2 & 1.24 \\
\hline & Tubular adenoma & 2 & 1.24 \\
\hline & Benign phyllodes tumor & $2^{\mathrm{a}}$ & 1.24 \\
\hline & Benign fibrous histiocytoma & 1 & 0.62 \\
\hline & Lipoma & 1 & 0.62 \\
\hline \multirow[t]{2}{*}{ Precursor lesions } & LCIS & $1^{\mathrm{a}}$ & 0.62 \\
\hline & Paget -carcinoma in situ & 1 & 0.62 \\
\hline \multirow[t]{7}{*}{ Malignant tumors } & Invasive carcinoma ,no special type & $43^{\mathrm{b}}$ & 26.7 \\
\hline & Metaplastic carcinoma & $3^{\mathrm{c}}$ & 1.86 \\
\hline & Mucinous carcinoma & 1 & 0.62 \\
\hline & Paget disease & $1^{\mathrm{c}}$ & 0.62 \\
\hline & DCIS with microinvasion & 2 & 1.24 \\
\hline & Unclassified carcinoma & 2 & 1.24 \\
\hline & Undifferentiated pleomorphic sarcoma & 1 & 0.62 \\
\hline \multirow[t]{7}{*}{ Non neoplastic lesions } & Acute/ chronic mastitis & 12 & 7.45 \\
\hline & Fat necrosis & 1 & 0.62 \\
\hline & Fibrocystic disease & 6 & 3.72 \\
\hline & Duct ectasia & 7 & 4.34 \\
\hline & Lobular granulomatous mastitis & 1 & 0.62 \\
\hline & Accessory breast & 1 & 0.62 \\
\hline & Tuberculous mastitis & $1^{\mathrm{b}}$ & 0.62 \\
\hline Lesions of male breast & Gynaecomastia & 4 & 2.48 \\
\hline Total & & 161 & 100 \\
\hline
\end{tabular}

* a, b, c represent cases with dual lesions 


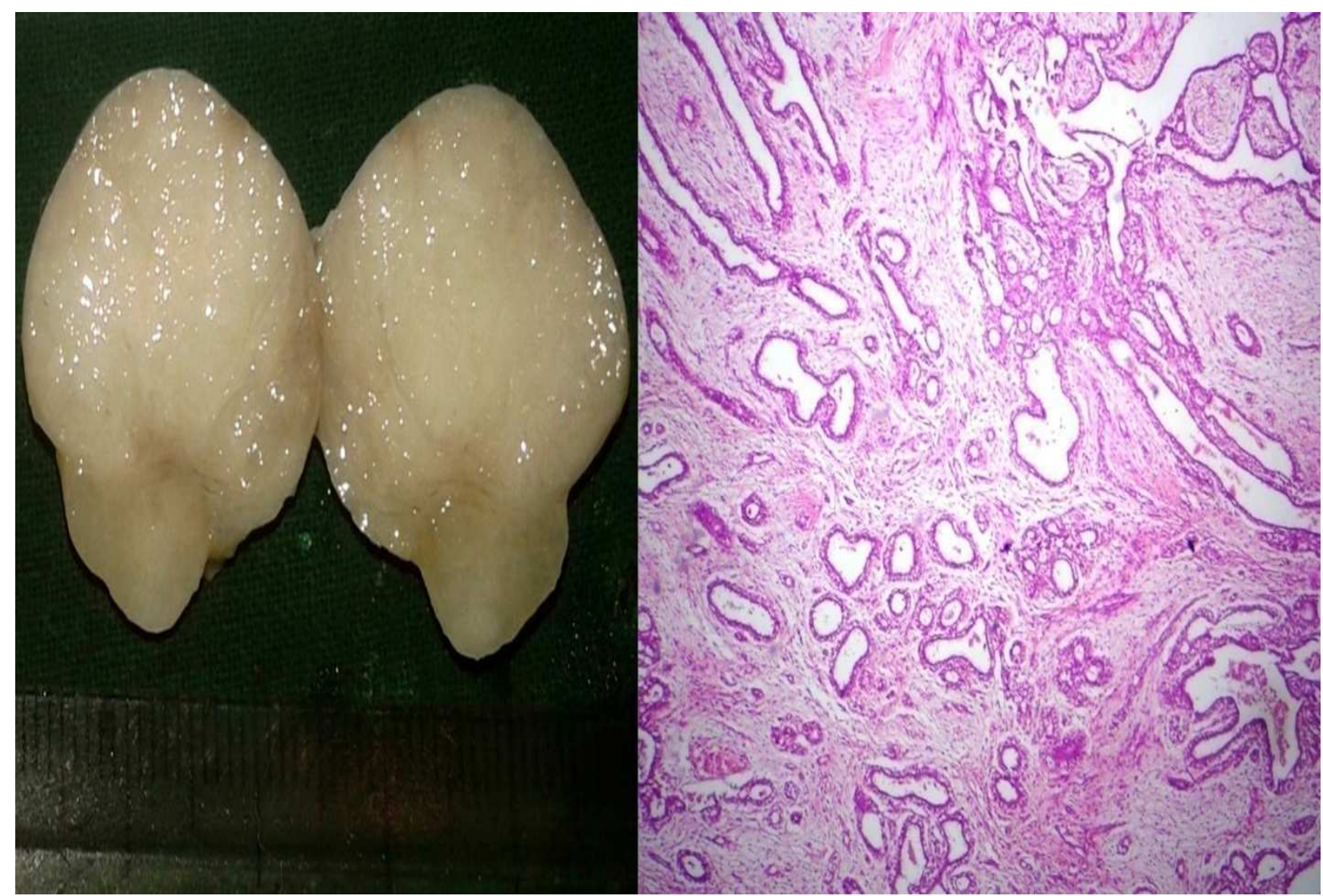

Figure-1: Photograph showing gross appearance and microscopy (HE X100) of fibroadenoma

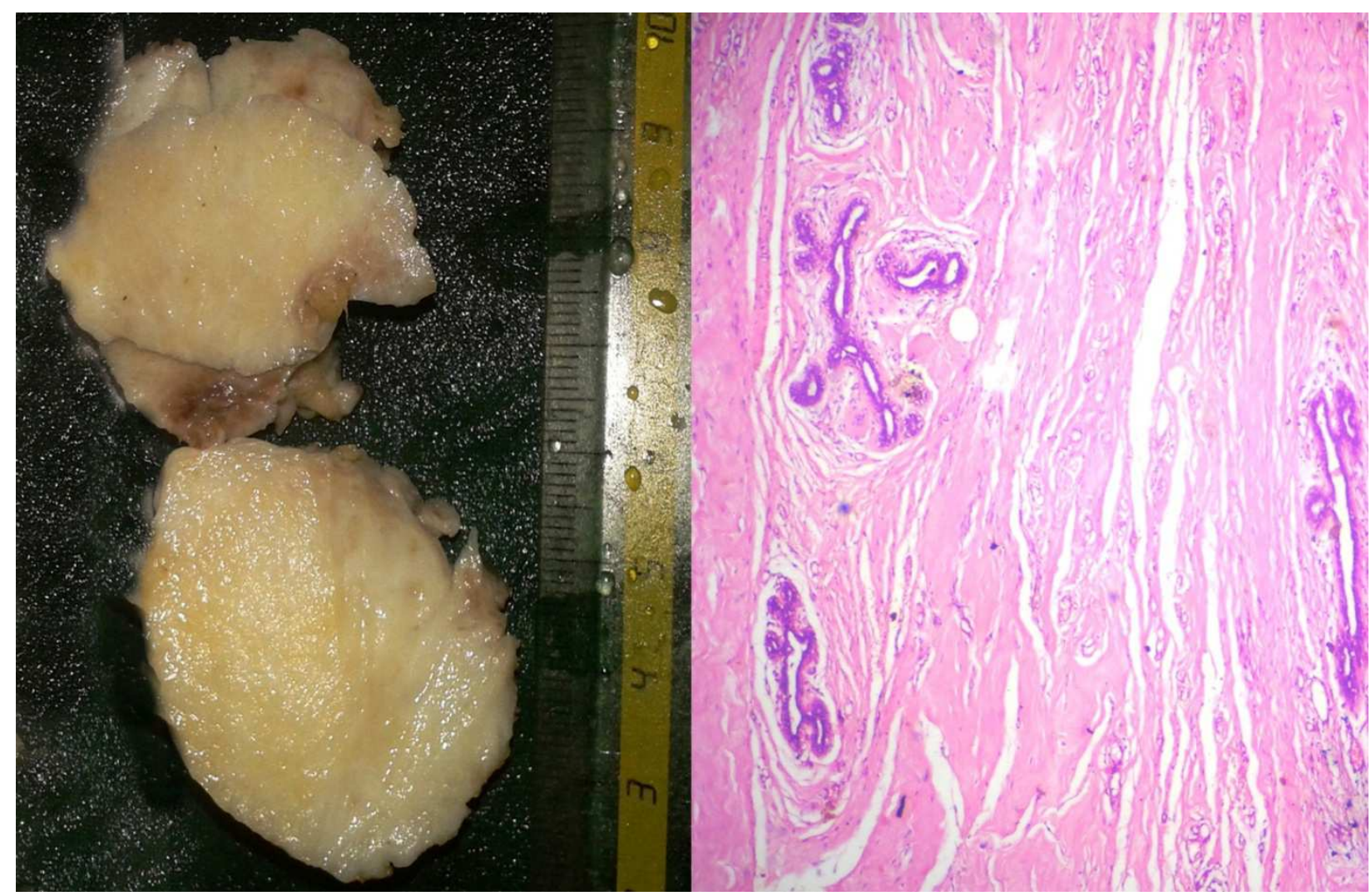

Figure-2: Photograph showing gross appearance and microscopy (HE X100) of mammary hamartoma 

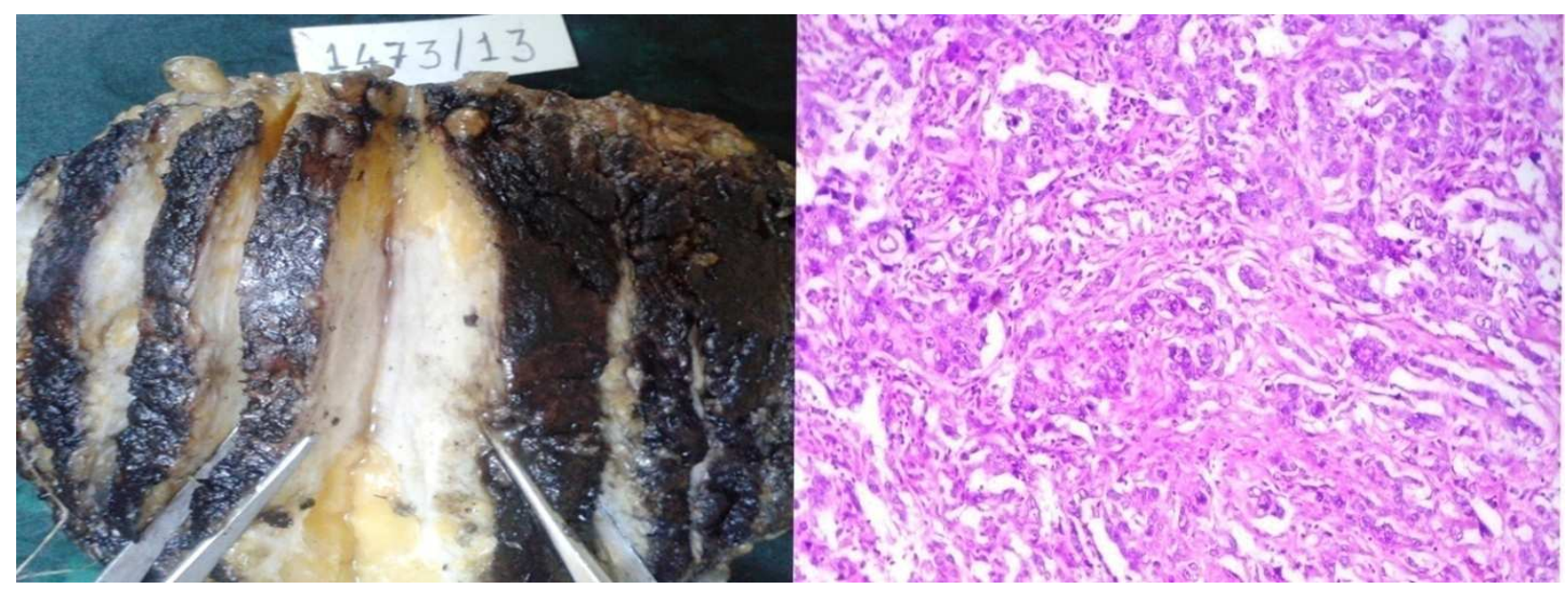

Figure-3: Photograph showing gross appearance and microscopy (HE X100) of invasive carcinoma- no special type
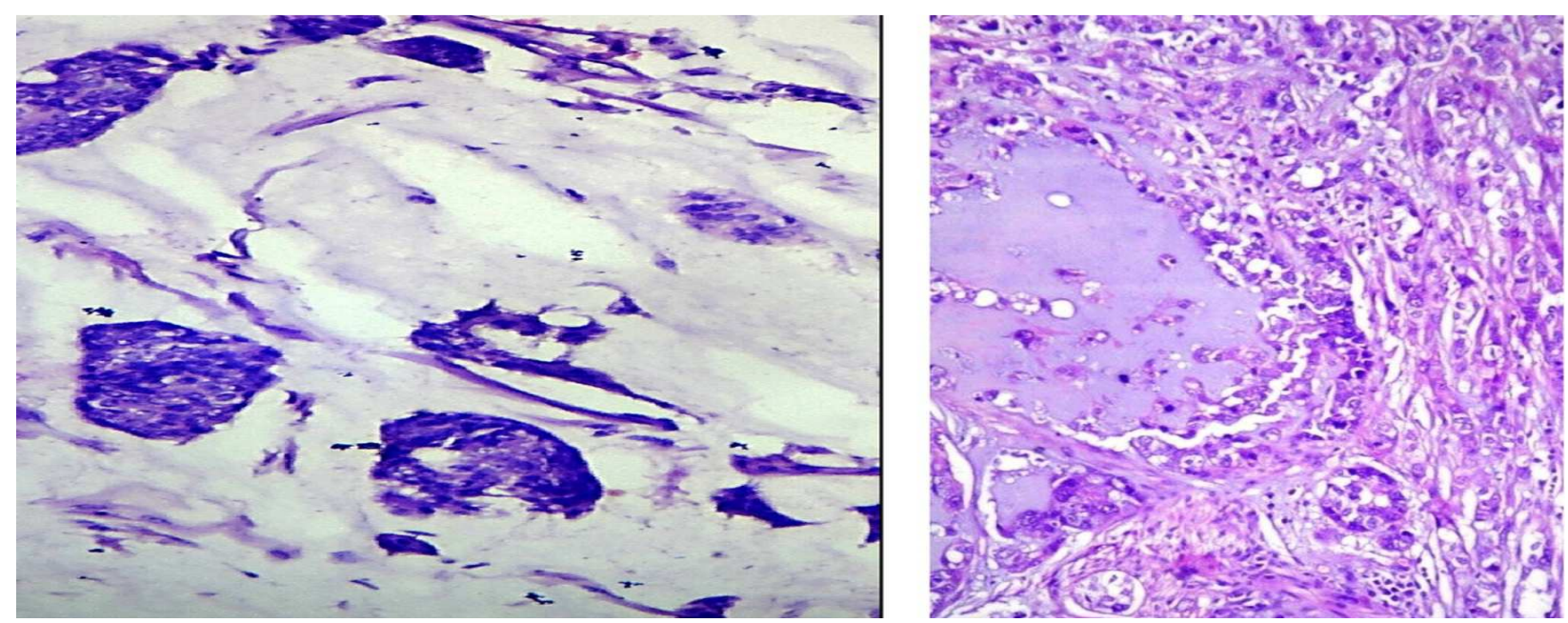

Figure-4: Photomicrograph of matrix producing carcinoma (left) and mucinous carcinoma (right) (HE X100)

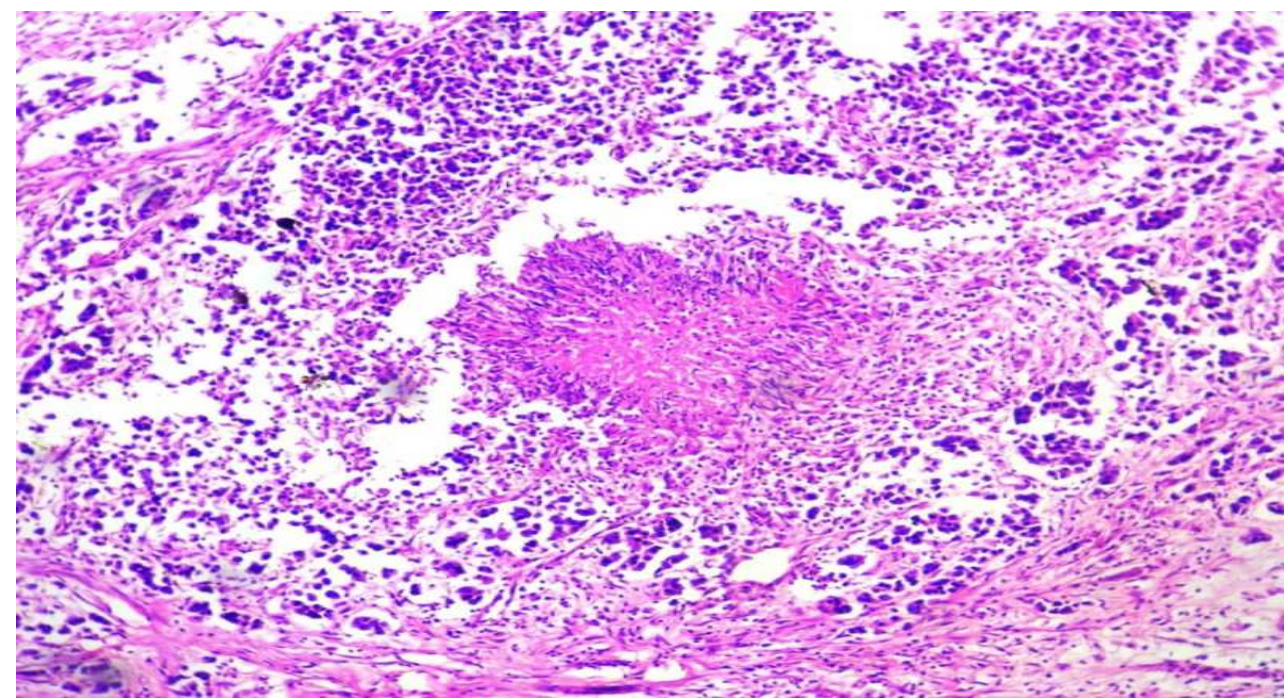

Figure-5: Photomicrograph showing coexistent invasive carcinoma no special type and tuberculosis breast (HE X100). 
Precursor lesions were found in 2 cases. There was one patient with lobular carcinoma in situ (45 year old female) who also had benign phyllodes tumor in the same breast. One 65 year old patient had Paget disease-carcinoma in situ.

Non neoplastic lesion were seen in 29 women. Mastitis was the commonest nonneoplastic lesion. One patient had coexistent invasive carcinoma no special type with tuberculosis (Figure -5). There were four cases of gynecomastia. Out of the 4 cases, 3 cases were less than 30 years age, and one case was in $7^{\text {th }}$ decade.

Neoplastic Lesions- The neoplastic lesions were most frequently located in upper outer quadrant (23 cases) followed by upper inner quadrant (19 cases) and multiple quadrants. Modified radical mastectomy (44 cases) was the most commonly received specimen for malignant breast tumors. For benign tumors (total 76 cases), nature of specimen was excisional biopsy in 74 cases and quadrantectomy in 2 cases.

Fibroadenoma was most frequently found in second decade followed by third and fourth decades Hamartoma was commonly seen in $3^{\text {rd }}$ and $4^{\text {th }}$ decades. There were no cases of benign tumors beyond $5^{\text {th }}$ decade. In contrast to benign breast tumours, all the cases of malignant tumours were beyond $4^{\text {th }}$ decade and there were no cases in $2^{\text {nd }}$ and $3^{\text {rd }}$ decade. Invasive carcinoma NST was most commonly seen in $7^{\text {th }}$ decade $\left(12\right.$ cases) and $4^{\text {th }}$ decade $(12$ cases $)$ followed by $6^{\text {th }}$ decade (11 cases). In 4 cases, bilateral fibroadenomas were seen.

Lymph node metastasis could be studied in 44 cases of invasive carcinoma who had undergone modified radical mastectomy. Out of 39 cases of Invasive carcinoma- No Special Type, 24 cases [61\%] showed lymph node metastasis. Lymph node metastasis was not seen in any other type.

Grading was done in 34 cases of invasive carcinoma. Out of these 34 cases, majority (24 cases) had grade II invasive carcinoma. Mucinous carcinoma was grade II. Out of three cases of metaplastic carcinoma grading was done in only one case [grade II]

The lesions in adjacent breast could be studied in total 46 cases (44 MRM and 2 simple mastectomies). Fibrocystic change was the most common lesion (16 cases) found in breast adjacent to malignant tumors solely or in association with other lesions. DCIS was found in adjacent breast in 3 cases. The other lesions in adjacent breast were usual ductal hyperplasia (3 cases), duct ectasia, adenosis, and duct papilloma (1 case each).

\section{Non-neoplastic Lesions (Table No. 2)}

Among nonneoplastic lesions, mastitis was most common followed by duct ectasia and fibrocystic change. The nonneoplastic lesions were most frequent in $4^{\text {th }}$ decade.

Table No-2: Showing age wise distribution of nonneoplastic lesions.

\begin{tabular}{|c|c|c|c|c|c|c|c|c|}
\hline \multirow{2}{*}{$\begin{array}{l}\text { Sr. } \\
\text { No. }\end{array}$} & \multirow{2}{*}{ Diagnosis } & \multicolumn{6}{|c|}{ Age in years } & \multirow{2}{*}{ Total } \\
\hline & & $11-20$ & 21-30 & $31-40$ & $41-50$ & $51-60$ & 61-70 & \\
\hline 1 & $\begin{array}{c}\text { Acute/ chronic } \\
\text { Mastitis }\end{array}$ & 1 & 1 & 4 & 3 & 2 & 1 & 12 \\
\hline 2 & Fat necrosis & - & - & - & - & - & 1 & 1 \\
\hline 3 & Fibrocystic change & - & 1 & 3 & 1 & 1 & - & 6 \\
\hline 4 & Duct ectasia & - & 1 & 3 & 2 & - & 1 & 7 \\
\hline 5 & $\begin{array}{l}\text { Lobular granulomatous } \\
\text { mastitis }\end{array}$ & - & - & 1 & - & - & - & 1 \\
\hline 6 & Accessory breast & 1 & - & - & - & - & - & 1 \\
\hline 7 & Tuberculous mastitis & - & - & 1 & - & - & - & 1 \\
\hline & Total & 2 & 3 & 12 & 6 & 3 & 3 & 29 \\
\hline
\end{tabular}




\section{Discussion}

We have studied and analysed various neoplastic and nonneoplastic breast lesions from the breast specimens received in our histopathology section and correlated the histopathology with clinical parameters. We came across a variety of different lesions including benign and malignant tumors, nonneoplastic lesions as well as few lesions of male breast.

The benign tumors outnumbered all the other lesions, with fibroadenoma being the commonest entity. Table no. 3 shows the observations of different other authors who studied benign tumours of breast. Fibroadenomas had the highest frequency among the benign breast tumors in all the studies. In the present study, we observed that maximum number of cases occurred between 11-20 years, followed by $3^{\text {rd }}$ and $4^{\text {th }}$ decade. Oluwole et al [6] and Raju et al [7] also observed that the commonest age group was 15-25 years. Haque et al [8] found that 30-40 years was the most common age group for fibroadenoma.

Table No.-3: Showing Frequency distribution of various benign breast tumours.

\begin{tabular}{|c|c|c|c|c|c|}
\hline Sr. No. & Authors & $\begin{array}{c}\text { Siddiqui } \\
\text { et al }[2003]^{3}\end{array}$ & $\begin{array}{c}\text { Olu-eddo } \\
\text { et al }[2011]^{4}\end{array}$ & $\begin{array}{l}\text { Mudholkar et al } \\
{\left[{ }_{[2012}\right]^{5}}\end{array}$ & Present study \\
\hline & $\begin{array}{l}\text { Total no. of benign } \\
\text { tumours }\end{array}$ & 645 & 944 & 127 & 76 \\
\hline \multirow{2}{*}{1} & \multirow{2}{*}{ Fibroadenoma } & 556 & 803 & 111 & 60 \\
\hline & & $86.20 \%$ & $85.06 \%$ & $87.40 \%$ & $78.94 \%$ \\
\hline \multirow[t]{2}{*}{2} & \multirow{2}{*}{$\begin{array}{l}\text { Benign Phyllodes } \\
\text { tumour }\end{array}$} & 19 & 34 & 8 & 2 \\
\hline & & $2.94 \%$ & $3.60 \%$ & $6.29 \%$ & $2.63 \%$ \\
\hline \multirow{2}{*}{3} & \multirow{2}{*}{ Tubular adenoma } & 5 & 28 & 3 & 2 \\
\hline & & $0.77 \%$ & $2.96 \%$ & $2.36 \%$ & $2.63 \%$ \\
\hline \multirow{2}{*}{4} & \multirow{2}{*}{ Lactating adenoma } & 5 & 36 & - & - \\
\hline & & $0.77 \%$ & $3.81 \%$ & - & - \\
\hline \multirow{2}{*}{5} & \multirow{2}{*}{ Duct papilloma } & 35 & 23 & 3 & 2 \\
\hline & & $5.42 \%$ & $2.43 \%$ & $2.5 \%$ & $2.63 \%$ \\
\hline \multirow{2}{*}{6} & \multirow{2}{*}{ Hamartoma } & - & - & - & 8 \\
\hline & & & & & $10.52 \%$ \\
\hline \multirow{2}{*}{7} & \multirow{2}{*}{ Lipoma } & 10 & 15 & 1 & 1 \\
\hline & & $1.5 \%$ & $1.56 \%$ & $0.78 \%$ & $1.31 \%$ \\
\hline \multirow{2}{*}{8} & \multirow{2}{*}{$\begin{array}{l}\text { Benign fibrous } \\
\text { histiocytoma }\end{array}$} & 2 & - & - & 1 \\
\hline & & $0.31 \%$ & & & $1.31 \%$ \\
\hline \multirow{2}{*}{9} & \multirow{2}{*}{ Neurofibroma } & - & - & 1 & - \\
\hline & & & & $1 \%$ & \\
\hline \multirow{2}{*}{10} & \multirow{2}{*}{ Others } & 7 & 5 & - & - \\
\hline & & $1.08 \%$ & $0.52 \%$ & - & - \\
\hline
\end{tabular}

In our study, 3 cases showed features of complex fibroadenoma i.e. sclerosing adenosis, papillary apocrine change and cyst formation $>3 \mathrm{~cm}$. Azzopardi et al [9] observed apocrine metaplasia in 15\% of the cases. Shabtai et al [10] reported associated pathologies [sclerosing adenosis, duct ectasia, apocrine metaplasias etc.] in $48 \%$ of cases. Sklair-Levy et al [11] reported frequency of complex fibroadenoma to be $15 \%$.

Fibroadenoma with Infarction was found in one case. Varghas et al [12] reported infarcted myxoid fibroadenoma following fine needle aspiration. Skenderi et al [13] reported case of spontaneous infarction in fibroadenoma not associated with pregnancy or lactation or fine needle aspiration. In our case also the infarction was not related with pregnancy, lactation or FNAC. In our case the diagnosis of fibroadenoma with infarction was suggested on cytology. Fibroadenoma with infarction can pose diagnostic difficulties while reporting the cytology. But clinical and radiological correlation along with meticulous interpretation of cytological findings can lead to correct diagnosis. 
In our study, maximum malignant tumors were in $6^{\text {th }}$ decade followed by $7^{\text {th }}$ and $4^{\text {th }}$ decade. Mudholkar et al [5] found maximum incidence in $6^{\text {th }}, 5^{\text {th }}$ and $7^{\text {th }}$ decade respectively. Osteen et al [14] observed maximum incidence of breast cancer in the $7^{\text {th }}, 8^{\text {th }}$ and $6^{\text {th }}$ decades respectively.

In this study, the most common quadrant involved was upper outer quadrant (22.6\%) followed by upper inner quadrant (16.9\%) and multiple quadrants (11.32\%). Mudholkar et al [5] also found upper outer quadrant (42\%) as the most commonly involved quadrant. In the study of Osteen et al [14] upper outer quadrant was most commonly involved by invasive carcinoma followed by multiple quadrant involvement.

The frequency distribution of histological types of malignant breast tumors noted by different authors is shown in table no. 4. In all the studies, invasive carcinoma, no special type was the most common malignant neoplasm.

34 cases of malignant breast tumours were graded according to Nottingham modification of Bloom -Richardson grading system. The observations of present study and other studies are shown in table no. 5 .

In all the studies, grade II invasive breast carcinoma was the most common.

Table No-4: Showing Histological types of malignant breast tumors in different studies.

\begin{tabular}{|c|c|c|c|c|}
\hline Type & $\begin{array}{c}\text { Dauda } \\
\text { et al }[2011]^{15}\end{array}$ & $\begin{array}{l}\text { Mudholkar } \\
\text { et al [2012] }\end{array}$ & $\begin{array}{c}\text { Njeze } \\
\text { et al }[2014]^{16}\end{array}$ & Present study \\
\hline Total cases & 165 & 125 & 28 & 53 \\
\hline Invasive carcinoma-No Special Type & $78.8 \%$ & $88 \%$ & $53.6 \%$ & $81.13 \%$ \\
\hline Invasive Lobular Carcinoma & $6.7 \%$ & $0.75 \%$ & - & - \\
\hline Medullary carcinoma & $3.6 \%$ & $0.75 \%$ & $10.7 \%$ & - \\
\hline Mucinous carcinoma & $2.4 \%$ & $1.5 \%$ & $7.1 \%$ & $1.88 \%$ \\
\hline Invasive Papillary Carcinoma & $4.2 \%$ & $0.75 \%$ & $7.1 \%$ & - \\
\hline Metaplastic carcinoma & - & $1.5 \%$ & - & $5.66 \%$ \\
\hline Intracystic Papillary Carcinoma & - & $0.75 \%$ & - & - \\
\hline Cribriform carcinoma & - & - & - & - \\
\hline $\begin{array}{l}\text { Ductal carcinoma in situ with } \\
\text { microinvasion }\end{array}$ & - & - & - & $3.77 \%$ \\
\hline Paget disease & - & - & - & $1.88 \%$ \\
\hline Anaplastic carcinoma & $2.4 \%$ & - & - & - \\
\hline Mixed carcinoma & - & $3 \%$ & - & - \\
\hline Malignant phyllodes & $1.8 \%$ & $1.5 \%$ & - & - \\
\hline Sarcoma & - & $0.75 \%$ & - & $1.88 \%$ \\
\hline Others & - & $0.75 \%-$ & $17.8 \%-$ & $3.77 \%$ \\
\hline
\end{tabular}

Others- The other malignant tumors in our study include two cases of unclassified carcinoma, in Mudholkar et al study [5] include one case of collision neoplasm. The other malignant tumors reported by Njeze et al [16] include one case of unspecified tumor, two cases of undifferentiated tumor and two cases of multiform carcinoma.

Lesions in the adjacent breast- In the present study, lesions in the breast adjacent to malignant tumor could be studied in total 46 cases including 44 modified radical mastectomy and 2 simple mastectomy specimens.

The most common lesion seen in breast adjacent to malignant tumours was fibrocystic change (34.78\%). Mudholkar et al [5] also found fibrocystic change as the most common lesion in adjacent breast (77.05\%).

Lymph node metastases: In our study axillary dissection was done in 44 cases of modified radical mastectomy. Lymph node metastasis was found in $61.53 \%$ cases, all of which were invasive carcinoma, no special type. Mudholkar et al [5] found it in $66 \%$ cases of invasive carcinoma, no special type. They also observed lymph node metastasis in cases of mixed carcinoma, invasive lobular carcinoma and medullary carcinoma. 
Truong et al [18] studied 542 women with pathologic T1-T2 breast carcinoma who had 1-3 positive lymph nodes and who had undergone mastectomy and received adjuvant systemic therapy without radiotherapy. They concluded that the presence of $>25 \%$ positive lymph nodes was an adverse prognostic factor in patients with 1-3 positive nodes and may be used to identify patients at high risks of postmastectomy locoregional and distant recurrence who may benefit with adjuvant radiotherapy and more aggressive systemic therapy regimens.

Yoshihara et al [20] concluded that lymphovascular invasion and tumor size are the most powerful independent predictors of axillary lymph node metastasis, followed by the retroareolar and lateral location of tumour in the breast and the presence of multiple foci.

Yip et al [21] documented node involvement in $7.7 \%$ of stage T1a tumors, $12.3 \%$ of T1b tumors, $29.2 \%$ of T1c tumors and $48.2 \%$ of $\mathrm{T} 2$ tumors. They found that tumor diameter $>2 \mathrm{~cm}$, presence of lymphovascular invasion and higher tumor grade were factors significantly associated with a higher risk of nodal metastases.

They concluded that in T1 tumors axillary lymph node dissection will overtreat almost $75 \%$ of cases; therefore a sentinel lymph node biopsy is justified in these tumors. Sentinel lymph node biopsy has been shown to reduce the complications of formal axillary dissection, such as shoulder stiffness, pain and lymphedema. In patients with T2 tumors, where almost $45 \%$ have lymph node involvement, sentinel node biopsy may not be cost effective [21].

Non-Neoplastic Conditions- The various non neoplastic breast lesions found by different authors are shown in table no. 6. Mastitis, fibrocystic change and duct ectasia were the relatively more common nonneoplastic lesions. Total 12 cases of acute and/or chronic inflammation and breast abscess were found in present study. Out of 12 cases, one patient was lactating. Age range was from 14-65 years. Mean age was 42.5 years. Haque et al [8] reported the age range between 1665 years and mean age of 38.8 years. Siddiqui et al [3] stated that the figures of breast abscesses are underestimated because most are drained and a minority are biopsied. Olu eddo et al [4] also observed low incidence of breast abscess. They commented that this may be attributed to the fact that most breast abscesses are incised and drained without histopathological diagnosis.

Table No.-5: Showing histological grading of invasive breast carcinomas.

\begin{tabular}{|c|c|c|c|c|c|}
\hline \multirow{2}{*}{$\begin{array}{c}\text { Sr. } \\
\text { No. }\end{array}$} & Author & $\begin{array}{c}\text { No. of cases in } \\
\text { which grading } \\
\text { was done }\end{array}$ & I & II & III \\
\cline { 4 - 6 } & & 975 & $11.38 \%$ & $59.17 \%$ & $29.47 \%$ \\
\hline 2 & $\begin{array}{c}\text { Siddiqui et al [2003] }]^{3} \\
\text { Lee et al } \\
{[2006]^{17}}\end{array}$ & 736 & $23 \%$ & $40 \%$ & $36 \%$ \\
\hline 3 & $\begin{array}{c}\text { Truong et al } \\
{[2005]^{18}}\end{array}$ & 542 & $7.7 \%$ & $49.6 \%$ & $42.6 \%$ \\
\hline 4 & $\begin{array}{c}\text { Vegt } \\
\text { et al [2007] }\end{array}$ & 242 & $23.5 \%$ & $45.3 \%$ & $30.9 \%$ \\
\hline 5 & Present study & 34 & $23.52 \%$ & $70.58 \%$ & $5.88 \%$ \\
\hline
\end{tabular}

Total 6 cases of fibrocystic disease were observed in present study. Age range was from 28-55 years. Mean age was 41 years. Average size was $2.66 \mathrm{~cm}$. Siddiqui et al [3] found that the mean age at diagnosis was 35 years. Olu eddo et al [4] reported age range 13-76 years, with a mean age of 30 years.

Total 7 cases of duct ectasia were observed in present study with frequency of $4.3 \%$. This is comparable with findings of Siddiqui et al [3] and Olu eddo et al[4] who reported frequency $5.3 \%$ and $2.4 \%$ respectively. 
Table No.-6: Benign non-neoplastic conditions.

\begin{tabular}{|c|c|c|c|c|c|c|c|}
\hline $\begin{array}{c}\text { Sr. } \\
\text { no. }\end{array}$ & Diagnosis & \multicolumn{2}{|c|}{ Siddiqui et al [2012] } & Olu eddo et al [2011] & \multicolumn{2}{c|}{ Present study } \\
\hline & Total cases & \multicolumn{2}{|c|}{3279} & \multicolumn{2}{|c|}{1864} & \multicolumn{2}{c|}{161} \\
\hline 1 & Acute and chronic mastitis & 224 & $6.8 \%$ & 36 & $1.3 \%$ & 1 & 0.62 \\
\hline 2 & $\begin{array}{c}\text { Chronic granulomatous } \\
\text { mastitis }\end{array}$ & 45 & $1.3 \%$ & 25 & - & 1 & $0.62 \%$ \\
\hline 3 & $\begin{array}{c}\text { Lobular granulomatous } \\
\text { mastitis }\end{array}$ & - & - & - & $1.6 \%$ & 1 & $0.62 \%$ \\
\hline 4 & Fat necrosis & 17 & $0.5 \%$ & 30 & $23.8 \%$ & 6 & $3.72 \%$ \\
\hline 5 & Fibrocystic change & 457 & $14 \%$ & 444 & $2.4 \%$ & 7 & $4.34 \%$ \\
\hline 6 & Duct ectasia & 175 & $5.3 \%$ & 44 & - & 1 & $0.62 \%$ \\
\hline 7 & Accessory breast & - & - & - & & & $12 \%$ \\
\hline
\end{tabular}

In present study single case of tuberculosis was seen in association with infiltrating ductal carcinoma, no special type. Munjal et al [22] reported six cases of tuberculous axillary lymphadenitis co existing with invasive ductal carcinoma of breast. Dave et al [23] also reported rare co existence of breast cancer and breast tuberculosis in 65 year old women.

Lesions of Male Breast- Gynecomastia-In the present study we found 4 cases of gynecomastia with frequency of $2.5 \%$. Age range was from 19-69 years. Mean age was 32.2 years. Olu Eddo et al [4] reported incidence of $2 \%$. Haque et al [8] reported an incidence of $8.66 \%$ and average age of 20 years.

Johnson et al stated that initial first step should be ruling out pseudogynecomastia by history taking and physical examination. A stepwise approach that includes imaging and laboratory tests to exclude neoplasms and endocrinopathies may facilitate cost-effective diagnosis [24].

\section{Conclusion}

We have studied 161 cases of breast lesions histopathologically, which has given us the information as, neoplastic lesions were more common than nonneoplastic lesions. The benign tumors were most frequent in second, third and fourth decades, malignant tumours were seen beyond $4^{\text {th }}$ decade. The nonneoplastic lesions were common in $4^{\text {th }}$ decade. All the tumors involved upper outer quadrant most frequently. Fibroadenoma was the most common benign tumor. Invasive carcinoma - No special type was the most common malignant tumor. Mastitis was the most common nonneoplastic lesion. Histopathological study plays very important role in diagnosis of breast lesions and hence in treatment and prognosis.

\section{Funding: Nil, Conflict of interest: None. Permission of IRB: Yes}

\section{References}

1. Lakhani S, Ellis I O, Schnitt S J, Tan P H, Van der vijver M J World Health Organization Classification of tumours of breast, Lyon, IARC press, 2012.
2. Dhillon PK, Breast Cancer Factsheet. South asia network for chronic disease. Public Health Foundation of India 2011.

3. Siddiqui M S, Kayani N, Gill M S, Pervez S, Aziz S A, Muzaffar S,Setna Z, Israr M, Hassan S H Breast diseases: a histopathological analysis of 3279 cases at tertiary care centre in Pakistan . JPMA 2003 53:94

4. Olu-Eddo AN, Ugiagbe EE. Benign breast lesions in an African population:A 25 year histopathological review of 1864 cases. Niger Med J. 2011 Oct;52(4): 211-6. doi: 10.4103/0300-1652.93790.

5. Mudholkar VG, Kawade SB, Mashal SN. Histopathological study of neoplastic lesions of breast. Ind Med Gazette 2012 Sept :353-64.

6. Oluwole, Soji F, Harold P, Analysis of benign breast disease in blacks. Am J Surg. 1979 Jun;137(6):786-9.

7. Raju GC, Jankey N, Narayansingh V. Breast disease in young west Indian women: an analysis of 1051 cases. Postgrad Med J. 1985 Nov; 61(721):977-8. 
8. Haque R, Tyagi SP, Khan MH, Gahlaut YVS, Breast lesions, A clinicopathological study of 200 cases of breast lumps. Ind J Surg 1980;42:419-425.

9. Azzopardi JG, Chepick OF, Hartmann WH, Jafarey NA. The world health organization .Histological typing of breast tumors. Am J Clin Pathol 1982;78:806-816.

10. Shabtai M, Saavedra-Malinger P, Shabtai EL, Rosin D, Kuriansky J, Ravid-Magido $M$ et al. Fibroadenoma of the breast :Analysis of associated pathological entities-A different risk marker in different age groups for concurrent breast cancer IMAJ 2001:3 813-817.

11. Sklair-Levy M, Sella T, Alweiss T, Cracium I, Libson E, Mally B. Incidence and management of complex fibroadenoma AJR Am J Roentgenol. 2008 Jan;190(1):214-8.

12. Varghas MP, Merino MJ Infarcted myxoid fibroadenoma following fine needle aspiration Arch Pathol Lab Med. 1996 Nov;120(11):1069-71.

13. Skenderi F, Krakonja F, Vranic S. Infarcted fibroadenoma of the breast :report of two new cases with review of literature Diagn Pathol. 2013 Feb 27;8: 38. doi: 10.1186/1746-1596-8-38.

14. Osteen RT,Karnell LH. The national cancer data base report on breast cancer. Cancer. 1994 Apr 1;73 (7):1994-2000.

15. Dauda AM, Misauno MA, Ojo EO. Histopathological types of breast cancer in Gombe north eastern Nigeria: A seven year review. African journal of reproductive health 2011 Mar 15(1):107-110

16. Njeze G E .Breast lumps: A 21 year single centre clinical and histological analysis, Nigerian journal of surgery. 2014 Jan -June . 20(1) 38-41.

17. Lee AHS, Gillett CE, Ryder K, Fentiman IS, Miles DW. Millis RR, Different patterns of inflammation and prognosis in invasive carcinoma of breast. Histopathology. 2006 May;48(6):692-701.

18. Truong PT, Berthelet E, Lee J, Kader H, Olivotto I A. The prognostic significance of the percentage of positive /dissected axillary lymph nodes in breast cancer recurrence and survival in patients with one to three positive axillary lymph nodes. Cancer. 2005 May 15; 103 (10):2006-14.

19. Van der Vegt B, Dee Roos M A J , Peterse J L, Patriarca C, Hilkens J, De Bock G H \& Wessling J. The expression pattern of MUC1 (EMA) is related to tumour characteristics and clinical outcome of invasive ductal breast carcinoma. Histopathology. 2007. 51: 322-335.

20. Yoshihara E, Smeets A, Laenen A, Reynders A, Soens J, Van Ongeval C et al Predictors of axillary lymph node metastases in early breast cancer and their applicability in clinical practice. Breast. 2013 Jun; 22(3):357-61. doi: 10.1016/j.breast.2012.09.003. Epub 2012 Sep 28.

21. Yip CH, Taib NA, Tan GH, Ng KL, Yoong BK, Choo WY Predictors of axillary lymph node metastases in breast cancer: is there role for minimal axillary surgery? World J Surg. 2009 Jan;33(1):54-7. doi: 10. 1007 /s00268-008-9782-7.

22. Munjal K, Jain VK, Agrawal A, Bandi PK .Co existing tubercular axillary lymphadenitis with carcinoma breast can falsely overstage the diseasecase series. Ind J Tuberc 2010;57:104-107.

23. Dave R, Dhruva G, Agravat A. Breast cancer and breast tuberculosis: a rare coexistence. Ind J Res Med, 2014; 3(1): 108-110.

24. Johnson RE, Murad MH. Gynecomastia: pathophysiology, evaluation, and management. Mayo Clin Proc. 2009 Nov; 84(11):1010-5. doi: 10.1016/ S0025-6196(11)60671-X.

\section{How to cite this article?}

Sulhyan K.R, Anvikar A.R, Mujawar I.M, Tiwari H. Histopathological study of breast lesions. Int J Med Res Rev 2017;5(01):32-41. doi:10.17511/ijmrr. 2017.i01.05. 